\title{
PREDICTION AND PRECONDITIONS OF COMPLICATED COURSE OF TRAUMATIC INJURY OF THE LIVER
}

\author{
Bukovinian State Medical University, Chernivtsi
}

\begin{abstract}
Summary. The article presents the results of a study of immunological prerequisites of complications after traumatic damage of the liver through the study of nonspecific immune defense and the effects of the syndrome of mu-
\end{abstract}

Introduction. Liver injury remains an important and urgent problem of surgery, because there is still a large percentage of cases in the structure of the injury and the development of complications in the postoperative period. Damage of the liver in abdominal trauma is $13,7-25,9 \%$ of cases and mortality can reach $28 \%$. Complications after liver injury can reach $14,8-42 \%$ [1-4].

Material and methods. The study included 40 victims with dominant liver injury (ISS $>16$ points), including 29 men $(72,5 \%)$ and 11 women $(27,5 \%)$. The average age was $37 \pm 8$ years. All the patients were operated. For the prognosis of post-traumatic postoperative period was used algorithm, which consists of the following factors: the extent and duration of anemia, degree of shock on admission, scoring assessment on a scale APACHE II, MODS, ISS, duration of surgery, the index Algovera, the development of multiple organ failure, existing comorbidities.

Results and discussion. Special places in the structure of social problems take a traumatic injury, especially a polytrauma. This is explained by many factors, among which a special place take age and gender features. Also note the steady increase in mortality, which is $26 \%$ depending on the severity of the injury and mainly $80 \%$ are men. A particularly adverse course of traumatic liver injury occupied among the elderly. Also among elderly patients disappear the differences in the proportion of traumatic liver injury between men and women. This is due to the increase in life expectancy in developed ltiple organ failure in the formation of postoperative complications in liver injury.

Key words: abdominal trauma, complications, immunological changes, liver injury.

countries and more mobility of the elderly population, due to the development of medicine and engineering. Also, according to research Major Trauma Outcome Study, found that mortality due to injury among older people three times higher than in people under the age of 55 years, which is associated with plenty complications of abdominal trauma.

Benchmarks of immunological changes were determined in liver trauma victims with mild to moderate severity: phagocyteic index $64,27 \pm 2,19 \%$, the number of phagocytic $3,42 \pm 0,17$, completeness phagocytosis index $1,13 \pm 0,05,71$ CIC $33 \pm 3,46$ units. Nonspecific immune defense were determined not only to confirm the effectiveness of the proposed algorithm, but also for the analysis of complications depending on the amount and character of damage. So for the damaged of liver the indicators of phagocytosis and CIC had the following character (tab. 1).

A special place in determining and monitoring the progress of post-traumatic process were determined by the level of middle mass molecules that characterize the level of endogenous intoxication (tab. 2).

As the table shows indicators middle mass molecules differed between the groups of patients (main group II) at the stage of hospitalization differed by $25 \%$ compared to the control group, which corresponded to the severity of the damage and the level of endogenous intoxication.

In determining the effectiveness of selected indicators for ballroom proposed algorithm com-

Table 1

Dynamic growth and nonspecific resistance of blood and circulating immune complexes in patients with liver injury

\begin{tabular}{|c|c|c|c|c|c|c|}
\hline & \multirow{2}{*}{$\begin{array}{c}\text { Control } \\
\text { group } \\
\mathrm{n}=15\end{array}$} & \multicolumn{5}{|c|}{ Postoperative Day } \\
\cline { 3 - 7 } & $\mathrm{n}=40$ & $\begin{array}{c}\text { 1-nt } \\
\mathrm{n}=40\end{array}$ & $\begin{array}{c}5 \text {-th } \\
\mathrm{n}=40\end{array}$ & $\begin{array}{c}7 \text {-th } \\
\mathrm{n}=40\end{array}$ & $\begin{array}{c}14 \text {-th } \\
\mathrm{n}=40\end{array}$ \\
\hline Phagocytic index, \% & $65,14 \pm 3,48$ & $\begin{array}{c}5,, 50 \pm 4,22 \\
\mathrm{p}>0,05\end{array}$ & $\begin{array}{c}63,65 \pm 3,17 \\
\mathrm{p}>0,7\end{array}$ & $\begin{array}{c}64,88 \pm 2,86 \\
\mathrm{p}>0,9\end{array}$ & $\begin{array}{c}42,00 \pm 2,13 \\
\mathrm{p}<0,001\end{array}$ & $\begin{array}{c}24,08 \pm 1,14 \\
\mathrm{p}<0,001\end{array}$ \\
\hline Phagocytic number & $3,26 \pm 0,12$ & $\begin{array}{c}3,00 \pm 0,26 \\
\mathrm{p}>0,3\end{array}$ & $\begin{array}{c}2,95 \pm 0,23 \\
\mathrm{p}>0,2\end{array}$ & $\begin{array}{c}2,84 \pm 0,21 \\
\mathrm{p}>0,07\end{array}$ & $\begin{array}{c}2,42 \pm 0,20 \\
\mathrm{p}<0,001\end{array}$ & $\begin{array}{c}1,96 \pm 0,10 \\
\mathrm{p}<0,001\end{array}$ \\
\hline $\begin{array}{c}\text { Index completion of } \\
\text { phagocytosis }\end{array}$ & $1,17 \pm 0,06$ & $\begin{array}{c}1,59 \pm 0,20 \\
\mathrm{p}<0,05\end{array}$ & $\begin{array}{c}1,44 \pm 0,20 \\
\mathrm{p}>0,1\end{array}$ & $\begin{array}{c}1,46 \pm 0,19 \\
\mathrm{p}>0,1\end{array}$ & $\begin{array}{c}1,29 \pm 0,17 \\
\mathrm{p}>0,4\end{array}$ & $\begin{array}{c}0,65 \pm 0,17 \\
\mathrm{p}<0,01\end{array}$ \\
\hline $\begin{array}{c}\text { Circulating immune com- } \\
\text { plexes, units }\end{array}$ & $74,98 \pm 2,59$ & $\begin{array}{c}53,60 \pm 4,76 \\
\mathrm{p}<0,001\end{array}$ & $\begin{array}{c}93,76 \pm 5,57 \\
\mathrm{p}<0,01\end{array}$ & $\begin{array}{c}76,04 \pm 6,95 \\
\mathrm{p}>0,8\end{array}$ & $\begin{array}{c}221,60 \pm 8,26 \\
\mathrm{p}<0,001\end{array}$ & $\begin{array}{c}189,51 \pm 6,81 \\
\mathrm{p}<0,001\end{array}$ \\
\hline \hline
\end{tabular}

(C) V.P. Poliovyi, F.G. Kulachek, Y.V. Kulachek, 2015 
Dynamics of middle mass molecules in patients with liver injury in stages of treatment

\begin{tabular}{|c|c|c|c|c|}
\hline \multirow{2}{*}{ Study group } & \multicolumn{3}{|c|}{ Middle mass molecules, standard units } \\
\cline { 2 - 5 } & 1-th day & 3-rd day & 7-th day & 10-th day \\
\hline $\mathrm{I}$ & $0,198 \pm 0,012$ & $0,257 \pm 0,019$ & $0,262 \pm 0,013$ & $0,211 \pm 0,009$ \\
$\mathrm{n}=15$ & $\mathrm{p}<0,001$ & $\mathrm{p}<0,001$ & $\mathrm{p}<0,001$ & 0,001 \\
\hline $\mathrm{II}$ & $0,206 \pm 0,015$ & $0,359 \pm 0,013$ & $0,311 \pm 0,017$ & $0,227 \pm 0,021$ \\
$\mathrm{n}=40$ & $\mathrm{p}<0,001$ & $\mathrm{p}<0,001$ & $\mathrm{p}<0,001$ & $\mathrm{p}<0,001$ \\
\hline
\end{tabular}

Table 3

Immunological prerequisites score prediction intervals in post-traumatic complicated postoperative period

\begin{tabular}{|c|c|c|c|c|}
\hline \multirow{2}{*}{ Indices } & \multicolumn{4}{|c|}{ Prognostic score of postoperative complications (points) } \\
\hline & $25-38$ & $39-51$ & $52-89$ & 90 та $>$ \\
\hline Middle mass molecules, standard units & $\begin{array}{c}0,184 \pm 0,013 \\
\mathrm{p}<0,001\end{array}$ & $\begin{array}{l}0,249 \pm 0,011 \\
\mathrm{p}<0,001\end{array}$ & $\begin{array}{c}0,337 \pm 0,019 \\
\mathrm{p}<0,001\end{array}$ & $\begin{array}{c}0,411 \pm 0,015 \\
\mathrm{p}<0,001\end{array}$ \\
\hline $\operatorname{Ig} \mathrm{M}, \mathrm{g} / \mathrm{l}$ & $\begin{array}{l}1,22 \pm 0,03 \\
\mathrm{p}<0,05\end{array}$ & $\begin{array}{c}1,16 \pm 0,02 \\
\mathrm{p}<0,05\end{array}$ & $\begin{array}{l}1,02 \pm 0,05 \\
\mathrm{p}<0,05\end{array}$ & $\begin{array}{c}0,76 \pm 0,07 \\
\mathrm{p}<0,05\end{array}$ \\
\hline IgG, g/l & $\begin{array}{c}11,24 \pm 0,081 \\
\mathrm{p}<0,05\end{array}$ & $\begin{array}{c}10,06 \pm 0,062 \\
\mathrm{p}<0,05\end{array}$ & $\begin{array}{l}9,42 \pm 0,52 \\
\mathrm{p}<0,05\end{array}$ & $\begin{array}{l}8,32 \pm 0,27 \\
\mathrm{p}<0,05\end{array}$ \\
\hline $\begin{array}{l}\text { Activity of the complement system, } \\
\text { standard units }\end{array}$ & $\begin{array}{c}1,11 \pm 0,04 \\
\mathrm{p}<0,05\end{array}$ & $\begin{array}{c}1,16 \pm 0,02 \\
\mathrm{p}<0,05\end{array}$ & $\begin{array}{c}1,21 \pm 0,03 \\
\mathrm{p}<0,05\end{array}$ & $\begin{array}{l}1,28 \pm 0,01 \\
\mathrm{p}<0,05\end{array}$ \\
\hline
\end{tabular}

pared Ball indicators and data of middle mass molecules, immunoglobulins and complement activity (tab. 3).

In complicated traumatic liver injury observed increase in long (more than 72 hours) of middle mass molecules and had multiorgan failure in the postoperative period. Unfavorable factor was the increase in the average molecular weight of more than 210 conventional units over 3 days in patients with liver injury and the development of multiple organ failure was complicated course in $60,5 \%$ of cases. Also with prolonged duration of multiple organ failure syndrome (more then 48 hours) were observed changes in nonspecific level of immune defense: index of phagocytic index decreased by $(17,9 \%)$ and was in the control group $(51,88 \pm 2,42)$, the second main group $(46,51 \pm 3,68)$.

Although generalized not only performance of MODS scale but also clinical data and wound process we discovered interdependent evidence that these processes not only lead to the emergence of each other, but also can provoke the development of infectious complications due to a significant fall in resistance of the organism as a whole (tab. 4).

By the complicated course of liver trauma should be noted formation of subdiaphragmatic abscess, subhepatic abscesses, peritonitis and extraperitoneal secondary complications.

\section{Conclusion}

Thus, as a result of the analysis was performed between the reduction of nonspecific protection and complication after traumatic injury of the liver. Joining postoperative multi organ failure syndrome increases to $35,72 \%$ incidence of complicated course of liver trauma. The proposed algorithm allows to improve the prediction of postoperative course and to detect preclinical stage of formation of complicated course.

\section{Literature}

1. Абакумов М.М. Диагностика и лечение одновременных ранений груди и живота / М.М. Абакумов, А.Н. Смоляр, Т.Т. Ткешелашвили // Хирургия. - 2005. - № 1. - C. 4-8.

2. Абакумов М.М.Особенности диагностики и определения рациональной лечебной тактики при закрытой сочетанной травме живота / М.М. Абакумов, Н.В. Лебедев, В.И. Малярчук // Рос. мед. ж. - 2003. № 2. - С. 17-20.

3. Интегральные системы оценки тяжести состояния больных при политравме/ Б.Р. Гельфанд, А.И. Ярошецкий, Д.Н. Проценко [и др.] // Вестн. интенсив. терапии. -2004 . - № 1. - С. 1-10.

4. Кучерявченко В.В. Роль маркерів ендогенної інтоксикації в ідентифікації тяжкості перебігу травматичної хвороби у постраждалих із травмою печінки при політравмі / В.В. Кучерявченко // Мед. сьогодні і завтра. 2009. - № 3. - C. 96-99.

\section{ПРОГНОЗИРОВАНИЕ И ПРЕДРАСПОЛАГАЮЩИЕ ФАКТОРЫ РАЗВИТИЯ ОСЛОЖНЕННОГО ТЕЧЕНИЯ ТРАВМАТИЧЕСКОГО ПОВРЕЖДЕНИЯ ПЕЧЕНИ}

\section{В.П. Полевой, Ф.Г. Кулачек, Я.В. Кулачек}

Резюме. В статье представлены результаты исследования иммунологических условий осложнений после травматического повреждения печени на основе изучения неспецифической иммунной защиты и влияние синдрома 
полиорганной недостаточности на формирование послеоперационных осложнений при повреждении печени.

Ключевые слова: абдоминальная травма, осложнения, иммунологические изменения, травма печени.

\section{ПРОГНОЗУВАННЯ ТА ПЕРЕДУМОВИ РОЗВИТКУ УСКЛАДНЕНОГО ПЕРЕБІГУ ТРАВМАТИЧНОГО УШКОДЖЕННЯ ПЕЧІНКИ}

\section{В.П. Польовий, Ф.Г. Кулачек, Я.В. Кулачек}

Резюме. У статті представлені результати дослідження імунологічних передумов розвитку ускладнень після травматичного пошкодження печінки на основі вивчення неспецифічного імунного захисту та вплив синдрому поліорганної недостатності на формування післяопераційних ускладнень при пошкодженні печінки.

Ключові слова: абдомінальна травма, ускладнення, імунологічні зміни, травма печінки.

Буковинський державний медичний університет (м. Чернівці)

Рецензент - проф. В.В. Білоокий

Buk. Med. Herald. - 2015. - Vol. 19, № 1 (73). - P. 131-133

Надійшла до редакції 15.01.2015 року

(C) V.P. Poliovyi, F.G. Kulachek, Y.V. Kulachek, 2015

УДК 617.586-002.3/.4-089-085.477-02:616.379-008.64:616.89

\section{Д.С. Прийменко}

\section{ПСИХОЕМОЦЙНИЙ СТАН ХВОРИХ ІЗ ГНІЙНО-НЕКРОТИЧНИМИ УСКЛАДНЕННЯМИ СИНДРОМУ ДІАБЕТИЧНОЇ СТОПИ, ЯКІ ЗАСТОСОВУВАЛИ РІЗНІ ЗАСОБИ РОЗВАНТАЖЕННЯ КІНЦІВКИ}

Харківський національний медичний університет, м. Харків

Резюме. У статті міститься докладний опис психоемоційного стану 59 хворих на синдром діабетичної стопи з гнійно-некротичними ускладненнями. Ці пацієнти використовували різні засоби розвантаження для стопи в післяопераційному періоді. Запропонований нами пристрій для розвантаження стопи забезпечує кращу позитивну динаміку порівняно 3 такими ортопе-

Вступ. Об’єктивні показники життєдіяльності хворого, засновані на лабораторних та інструментальних методах дослідження, відіграють важливу роль у процесі хірургічного лікування. У той же час «для оцінки стану здоров'я людини необхідна думка самої людини, іiі суб'єктивне сприйняття власного «я» у конкретному соціально-біологічному середовищі» [6].

На наш погляд, найбільш повну картину перебігу захворювання дає комплексний підхід у лікувальному процесі, що включає в себе й вивчення якості життя хворого, пов'язаного з його здоров’ям (далі - ЯЖПЗ).

Вивчення ЯЖПЗ проводиться для оцінки нових технологій, реабілітаційних методик, впливу захворювання на фізичне, психологічне і соціальне функціонування пацієнта. Це додатковий критерій для визначення індивідуальної терапії, експертизи працездатності, аналізу співвідношення витрат $[1,5]$. Слід виділяти три основні складові ЯЖПЗ: фізичний (функціональний), психоемоційний стан, соціальний добробут.

Увага вчених зосереджена переважно на описі загальної характеристики ЯЖПЗ хворих на синдром діабетичної стопи (далі - СДС) у відда-

(с) Д.С. Прийменко, 2015 дичними засобами, як гіпсова лонгета і напівчеревик. Вивчення психоемоційного стану хворого дає можливість для більш ефективного лікування.

Ключові слова: синдром діабетичної стопи, психоемоційний стан, гнійно-некротичні ускладнення, розвантаження стопи.

леному періоді хірургічного лікування та в період реабілітації $[3,7]$. У даний час актуальним залишається питання про вплив використання різних засобів розвантаження стопи на ЯЖПЗ хворих на СДС із гнійно-некротичними ускладненнями в ранньому післяопераційному періоді.

Вбачається, що залежно від строків загоєння ран, перебігу патологічного процесу можуть змінюватися різноманітні показники, що характеризують хворого, у тому числі його психоемоційний стан.

Мета дослідження. Порівняти психоемоційний стан хворих $з$ гнійно-некротичними ускладненнями СДС, що застосовували гіпсову лонгету, напівчеревик i розроблений нами пристрій для розвантаження стопи (Патент на корисну модель 90977) [2] у післяопераційному періоді на етапі стаціонарного лікування.

Матеріал і методи. Усі прооперовані пацієнти, які застосовували один із засобів розвантаження стопи, були розподілені на три клінічні групи: до першої групи увійшло 18 осіб, які використовували напівчеревик; другу групу склали 19 осіб із гіпсовою лонгетою; до третьої групи - 22 особи з пристроєм для розвантаження стопи. Ко- 